\title{
Downregulated Chibby in laryngeal squamous cell carcinoma with increased expression in laryngeal carcinoma Hep-2 cells
}

\author{
JUE XU ${ }^{1 *}$, GANG REN ${ }^{1 *}$, DE-AN ZHAO ${ }^{2 *}$, BO-AN LI ${ }^{3}, \mathrm{CHENG}^{*} \mathrm{FU} \mathrm{CAI}^{4}, \mathrm{YI} \mathrm{ZHOU}^{4}$ and XIAN-YANG LUO ${ }^{4}$ \\ ${ }^{1}$ Department of Otolaryngology, The First Hospital Affiliated to Huzhou University Medical College, \\ Huzhou, Zhejiang 313000; ${ }^{2}$ Department of Otolaryngology, the 174th Hospital of PLA, Xiamen; ${ }^{3}$ State Key \\ Laboratory of Cellular Stress Biology, School of Life Sciences, Xiamen University, Xiamen; ${ }^{4}$ Department of \\ Otolaryngology, The First Affiliated Hospital of Xiamen University, Xiamen, Fujian 361003, P.R. China
}

Received June 12, 2014; Accepted August 3, 2014

DOI: $10.3892 /$ or.2014.3451

\begin{abstract}
Chibby (Cby) inhibits Wnt/ $\beta$-catenin-mediated transcriptional activation by competing with Lef-1 (the transcription factor and target of $\beta$-catenin) to bind to $\beta$-catenin. This suggests that Cby could be a tumor suppressor protein. In the present study, we examined Cby expression in laryngeal squamous cell carcinoma (LSCC) and its function and mechanism in laryngeal carcinoma cell lines. Cby expression levels were investigated by immunohistochemistry in a panel of 36 LSCC patient cases. The expression of $\beta$-catenin, c-myc and cyclin D1 in Hep-2 were determined through RT-PCR and western blot analysis. Activity of $\mathrm{Wnt} / \beta$-catenin signaling pathway after overexpression of Cby was measured by TCF/LEF luciferase reporter gene assay. Proliferation, clone forming ability, cell cycle distribution and cell apoptosis of Hep-2 cells were detected by MTT assay, plate colony forming assay, flow cytometry and TUNEL assay, respectively. This study showed that expression of Cby protein was strongly downregulated in LSCC tumor tissues in comparison to normal laryngeal mucosa samples. No significant correlation was found between the expression of Cby in tumor tissue and gender, age, clinical stage and tumor differentiation of laryngeal cancer patients. When Cby was overexpressed in Hep-2 cells, the expression of cyclin D1 was reduced and $\beta$-catenin activity was inhibited. Proliferation and plate colony forming assays revealed a significant inhibitory effect of Cby on growth and colony formation ability of Hep-2 cells after Cby overexpression in comparison to control and mock-infected cells. In addition, we also found that upregulated expression
\end{abstract}

Correspondence to: Dr Gang Ren, Department of Otolaryngology, The First People's Hospital of Huzhou, Huzhou, Zhejiang 313000, P.R. China

E-mail: 176164137@qq.com

*Contributed equally

Key words: Chibby, laryngeal squamous cell carcinoma, Wnt, signaling pathway of Cby resulted in accumulation of numbers of cells in G0/G1 phase with concomitant decrease in $\mathrm{S}$ phase by cell cycle assay. TUNEL staining demonstrated that, compared with the control group, the rate of apoptosis in the plv-cs2.0-Cby group was significantly increased. Taken together, downregulation of Cby was observed in LSCC, but with no significant correlation to the clinicopathological features of LSCC patients. Overexpression of Cby effectively suppressed laryngeal carcinoma cell growth and promoted its apoptosis. A better understanding of the mechanisms of Cby gene activation in LSCC could provide potential novel therapeutic targets for human laryngeal carcinoma.

\section{Introduction}

Laryngeal squamous cell carcinoma (LSCC), the second most common cancer of the head and neck region worldwide (1), occurs to a large extent in patients between 60 and 70 years old. Patients with LSCC have a poor survival, which has not improved over the last 30 years (2). Therefore, other effective means are required for treating LSCC, such as changing or modifying some important genes and their expression products. For instance, the Wnt/ $\beta$-catenin pathway as an effective molecular target for the therapy of cancer has attracted widespread attention $(3,4)$. Mutations in $\mathrm{Wnt} / \beta$-catenin pathway constituents have been linked to a number of human cancers derived from colorectal, ovarian, breast and neuroectodermal tissues (5-8). The determination of critical regulators of this pathway, therefore, provides an important means to identify novel therapeutic targets.

The Wnt/ $\beta$-catenin pathway stimulation and subsequent activation of cell growth-related target gene transcription have been well established. Canonical Wnt signaling initiates when Wnt ligands bind frizzled transmembrane receptors and low-density lipoprotein (LRP5/6) receptors (9). In cells that receive a Wnt signal, the key effector of the pathway, $\beta$-catenin, is stabilized by the inhibition of a cytoplasmic destruction complex, consisting of the adenomatous polyposis coli (APC), Axin, casein kinase I and glycogen synthase kinase $3 \beta$ (GSK3 $\beta$ ) (10). In the absence of Wnt signaling, $\beta$-catenin is phosphorylated by GSK-3 $\beta$ and casein kinase I and is further targeted for ubiquitin-mediated proteasomal 
degradation. Inhibition of the destruction complex following Wnt ligand binding enables accumulation of $\beta$-catenin in the cytoplasm. Stabilized $\beta$-catenin translocates to the nucleus and interacts with lymphocyte enhancer factor/T-cell factor (LEF/TCF) transcription factors as well as numerous co-factors to elicit changes in gene expression involved in cell growth and proliferation, such as cyclin D1 $(11,12)$ and c-myc $(13)$.

$\beta$-catenin and APC are key components of Wnt $/ \beta$-catenin signaling pathway. Analysis of $\beta$-catenin protein expression enabled the assessment of the biology of laryngeal cancer and it could be a prognostic factor of overall and disease-free survival, while measured on front tumor in patients with laryngeal cancer (14). In addition, the abnormal expression of $\beta$-catenin was closely related to differentiation, clinical stage and metastasis in laryngeal carcinoma (15). Recently, a study showed that supraglottic carcinoma was correlated with the abolishment of $\beta$-catenin from the membrane, which suggested that $\beta$-catenin was differently expressed in glottic and supraglottic carcinomas, leading to the distinct clinical behavior of these tumors (16). On the other hand, it has been found that the LOH of APC gene plays an important role in LSCC carcinogenesis and development $(17,18)$. These data suggest that the Wnt/ $\beta$-catenin signaling pathway may be involved in LSCC.

Chibby (Cby) is a newly found $\beta$-catenin binding partner, which is highly conserved throughout evolution from fly to human (19). Cby physically interacts with the C-terminal activation domain of $\beta$-catenin and represses $\beta$-catenin-mediated transcriptional activation by competing with TCF/LEF factors for $\beta$-catenin binding $(19,20)$. The second mode of action for Cby in inhibiting $\beta$-catenin signaling was previously identified $(20,21)$. Upon phosphorylation of Cby serine 20 by Akt kinase, Cby and 14-3-3 form a stable trimolecular complex with $\beta$-catenin and cooperate to promote the export of $\beta$-catenin from the nucleus to the cytoplasm, leading to downregulation of $\beta$-catenin-mediated transcriptional activation. The regulatory effect of Cby in the $\mathrm{Wnt} / \beta$-catenin signaling pathway suggests the biological importance of Cby as a potential tumor suppressor gene (19). However, a limited number of studies has shown that the expression of Cby was downregulated only in thyroid cancer, pediatric ependymomas and colon carcinoma cell lines (22-24); the expression of Cby and its role in LSCC remain poorly understood. In the present study, we demonstrated that Cby is strongly downregulated in the LSCC tissues. Enforced expression of Cby in Hep-2 laryngeal carcinoma cells resulted in inhibition of the cell growth and increased cell apoptosis. These findings suggest that Cby may be a tumor suppressor for the therapeutic targeting of this type of LSCC.

\section{Materials and methods}

Tissue samples. A total of 36 LSCC tissues and normal laryngeal mucosas were derived from the same patients who underwent primary surgery between July 2011 and March 2013 at the department of Otolaryngology in The First People's Hospital of Huzhou (Huzhou, Zhejiang, China). Of the 36 LSCC patients, 30 were men and 6 were women. The ages ranged from 43-77 years (median age, 61 years). According to the TNM classification of the International
Union Against Cancer and the American Joint Committee on Cancer (AJCC) (7th edition), the clinical staging of the LSCC tissues was I in 9 cases, II in 11 cases, III in 10 and IV in 6 cases. All the specimens were subjected to histological diagnosis by two pathologists in The First People's Hospital of Huzhou. On the basis of the diagnosis, the degree of LSCC tissue differentiation was high in 13 , moderate in 17 and poor in 6. Each tissue specimen, $0.5-1 \mathrm{~cm}^{3}$, was formalin-fixed and paraffin-embedded for histological and immunohistochemical studies. These patients had no history of LSCC and had not undergone radiotherapy or chemotherapy prior to operation. This study conforms to approved institutional guidelines. Informed consent was obtained from each patient.

Analysis of Cby protein expression by immunohistochemistry (IHC). IHC was performed according to the streptavidin-peroxidase (SP) (Maixin Bio, Fuzhou, China). Representative 5- $\mu \mathrm{m}$ tissue sections were dewaxed in xylene and rehydrated in graded ethanols. Antigen retrieval was enhanced by microwaving the slides in $0.01 \mathrm{M}$ citrate buffer ( $\mathrm{pH}$ 6.0). Endogenous peroxidase activity was quenched by treatment with peroxidase blocking solution (reagent $\mathrm{A}$ ) for $10 \mathrm{~min}$, followed by incubation with non-immune serum (reagent B) for $10 \mathrm{~min}$. Sections were subsequently incubated with human reacting, primary rabbit anti-PGEA1 (Novus Biologicals, Littleton, CO, USA; dilution $1: 5,000$ ) overnight at $4^{\circ} \mathrm{C}$. Bound primary antibody was detected using the biotin-streptavidin-peroxidase method (reagents $\mathrm{C}$ and D) and visualized using diaminobenzidine as the chromogen. Slides were counterstained with hematoxylin, dehydrated and mounted. For negative controls, PBS was added instead of the primary antibody.

All the slides were assessed by two pathologists and one of the investigators independently, and blinded to the case details. Nucleolus and/or cytoplasmic immunostaining of Cby were evaluated. Both intensity of staining and percentage of positive cells were taken into account and the following scoring system was used: 0 , no staining or weak staining in $<50 \%$ of tumor cells; 1 , weak staining in $50-75 \%$ of tumor cells or moderate staining in $25-50 \%$ of tumor cells; 2 , weak staining in $>75 \%$ of cells, moderate staining in 50-75\% of tumor cells or strong staining in $25-50 \%$ of tumor cells; and 3, moderate staining in $>75 \%$ or strong staining in $>50 \%$ of tumor cells. Cases with score 0 were considered negative and cases with scores 1,2 or 3 were considered weakly, moderately or strongly positive, respectively.

Lentiviral vector preparation. A lentiviral eukaryotic expression vector encoding the cDNAs of Cby was constructed to express Cby in vivo. The Cby promoter region (381 bp), a PCR product of cDNAs of Cby, was cloned into the $\mathrm{XbaI}$ and $M I u I$ restriction sites of the lentiviral vector plv-cs2.0 (from Professor Boan Li, Xiamen University, Xiamen, China). The primers for cDNAs of Cby with the addition of flanking $\mathrm{XbaI}$ and $M I u \mathrm{I}$ restriction sequences for cloning purpose and flag-tag sequences for distinguishing expression purpose were designed using design software Primer premier 5.0 (Premier, Canada) and synthesized (Sangon Biotech, Shanghai, China) as follows: forward, 5'-GCTCTAGAATGGACTACAAAGACGATGA CGACAAGATGCCTTTCTTTGGGAATACGG-3' (XbaI and flag-tag); reverse, 5'-CGACGCGTTCATTTTCTCTTC 
CGGCTGATC-3' (MIuI). The target DNA was purified and used to transform E. coli. The product plv-cs 2.0 -flag-Cby was confirmed by restriction analysis and sequencing. The plv-cs2.0-GFP vector or plv-cs2.0-flag-Cby vector, together with the two packaging plasmids (PHR and pVSVG) comprising packaging mix, were cotransfected into 293FT cells to produce the lentiviral viral stock plv-cs2.0-GFP ${ }_{\text {viral }}$ or plv-cs2.0-Cby ${ }_{\text {viral }}$ using TurboFect ${ }^{\mathrm{TM}}$ (Fermentas, Burlington, ON, Canada) according to the manufacturer's manual. The stock was enriched by ultracentrifugation for cell experiments, outlined by Kafri et al (25). Briefly, high-titer stocks were obtained by ultracentrifugation at $50,000 \mathrm{x}$ g for $2 \mathrm{~h}$ at $4^{\circ} \mathrm{C}$. The pellet was resuspended in PBS containing $1 \%$ bovine serum albumin and stored frozen at $-80^{\circ} \mathrm{C}$. The viral titers were determined with 293FT cells according to the manufacturer's manual.

Cell culture and infection. The human LSCC cell line Hep-2 (from Professor Boan Li, Xiamen University, Xiamen, China) was cultured in Dulbecco's modified Eagle's medium (DMEM; Gibco, Carlsbad, CA, USA), supplemented with $10 \%$ fetal bovine serum, $100 \mu \mathrm{g} / \mathrm{ml}$ streptomycin and $100 \mathrm{U} / \mathrm{ml}$ penicillin. Cells were maintained at $37^{\circ} \mathrm{C}$ in an incubator containing $5 \% \mathrm{CO}_{2}$. All infections utilized polybrene infection reagent (Millipore, USA) according to the manufacturer's instructions. Hep-2 cells were grown in three $3.5 \mathrm{~cm}^{2}$ plates to $~ 30 \%$ confluency: the first one, the control group, was treated with $2 \mu \mathrm{l}$ of polybrene alone; the second and third groups, LV-GFP or LV-Cby, were infected with plv-cs2.0-GFP ${ }_{\text {viral }}$ or plv-cs2.0Cby $_{\text {viral }}$ using $2 \mu 1$ of polybrene, respectively. Stably expressing Cby was generated in Hep- 2 cell lines and the cell clones were subcultured and maintained at the lowest lethal concentration of puromycin reagent (Santa Cruz Biotechnology, Santa Cruz, CA, USA) until all the control cells were dead.

Reverse transcription-PCR analysis. The methods of total RNA extraction from the group of control, LV-GFP and LV-Cby cells and cDNA synthesis were mentioned above. PCR amplifications of targeted $\beta$-catenin, c-myc, cyclin D1 and Cby reference and an 18sRNA positive control were performed with cDNA and primers using a thermal cycler (Mastercycler personal; Eppendorf, Hamburg, Germany). The reactions were performed in a final volume of $25 \mu \mathrm{l}$, containing (final concentration) $2.5 \mathrm{U}$ rTaq DNA polymerase, $1 \mathrm{x}$ rTaq DNA polymerase, $0.25 \mathrm{mM}$ each dNTPs and 100 pmol each specific primer. The primer sequences and the expected lengths of amplification fragments are listed as follows: $\beta$-catenin upstream primer, 5'-GATACCTCCCAAGTCCTGTATGAG-3' and downstream, 5'-GCATCAAACTGTGTAGATGGGATC-3'; 176 bp. C-myc upstream primer, 5'-CTGGTTCACTAAGTGCGTCTCC-3' and downstream: 5'-CACCGAGTCGTAGTCGAGGTC-3'; 292 bp. Cyclin D1 upstream primer, 5'-CAGGGATGG CTTTTGGGCTC-3' and downstream, 5'- TGGAGGCT CCAGGACTTTGC-3'; 189 bp. Cby upstream primer, 5'-TTTGGGAATACGTTCAGTCCG-3' and downstream, 5'-TCAGCCGCAAGAGATTGTTC-3'; 271 bp. 18sRNA upstream primer, 5'-GTCTGTGATGCCCTTAGATG-3' and downstream, 5'-AGCTTATGACCCGCACTTAC-3'; $177 \mathrm{bp}$. All PCR reactions were denatured at $95^{\circ} \mathrm{C}$ for $5 \mathrm{~min}$ as follows: $\beta$-catenin $\left(27\right.$ cycles of amplification at $95^{\circ} \mathrm{C}$ for
$30 \mathrm{sec}, 60^{\circ} \mathrm{C}$ for $20 \mathrm{sec}$ and $72^{\circ} \mathrm{C}$ for $\left.40 \mathrm{sec}\right)$; c-myc $(37$ cycles of amplification at $95^{\circ} \mathrm{C}$ for $30 \mathrm{sec}, 59^{\circ} \mathrm{C}$ for $20 \mathrm{sec}$ and $72^{\circ} \mathrm{C}$ for $40 \mathrm{sec}$ ); cyclin D1 (27 cycles of amplification at $95^{\circ} \mathrm{C}$ for $30 \mathrm{sec}, 63^{\circ} \mathrm{C}$ for $20 \mathrm{sec}$ and $72^{\circ} \mathrm{C}$ for $\left.40 \mathrm{sec}\right)$; Cby $(27$ cycles of amplification at $95^{\circ} \mathrm{C}$ for $30 \mathrm{sec}, 60^{\circ} \mathrm{C}$ for $20 \mathrm{sec}$ and $72^{\circ} \mathrm{C}$ for $40 \mathrm{sec}$ ); 18sRNA ( 17 cycles of amplification at $95^{\circ} \mathrm{C}$ for $30 \mathrm{sec}$, $57^{\circ} \mathrm{C}$ for $20 \mathrm{sec}$ and $72^{\circ} \mathrm{C}$ for $40 \mathrm{sec}$ ), with a final extension at $72^{\circ}$ for 5 min. Following $2 \%$ agarose gel electrophoresis and ethidium bromide staining, the PCR products were detected using Chemi-Doc XRS (Bio-Rad) under ultraviolet irradiation. Quantity One software (Bio-Rad) was used to quantify the relative mRNA expression of these genes by densitometry.

Western blot analysis. The three cell groups (control, LV-GFP and LV-Cby) were trypsinized, washed twice with ice-cold phosphate-buffered saline (PBS) and harvested in cell lysis buffer (50 mM Tris pH 7.4, $0.3 \mathrm{M} \mathrm{NaCl}, 5 \mathrm{mM}$ EGTA, $1 \mathrm{mM}$ EDTA, $0.5 \%$ Triton X-100, 0.5\% NP-40) containing a protease inhibitor cocktail (Huatesheng Biotech, Fushun, Liaoning, China). Cell lysates were briefly ultrasonicated for $2 \mathrm{sec}, 6$ times, and subsequently clarified by centrifugation at $12,000 \mathrm{x}$ g for $15 \mathrm{~min}$ at $4^{\circ} \mathrm{C}$. Supernatants were collected for further experiments. Protein concentrations were determined according to the Lowry method using bovine serum albumin (BSA) as a standard (26). A total of $80 \mathrm{~g}$ protein was separated by SDS-PAGE and transferred to a Hybond ECL polyvinylidene fluoride membrane. Membranes were blocked with $1 \mathrm{X}$ Tris-buffered saline (TBS) containing $5 \%$ non-fat dry milk for at least $1 \mathrm{~h}$ at room temperature. The blots were then incubated overnight at $4{ }^{\circ} \mathrm{C}$ with one of the following antibodies: anti- $\beta$-catenin $(92 \mathrm{kDa}$; ab32572; $1: 2,000)$, anti-c-myc (49 kDa; ab39688; $1: 750)$, anti- $\beta$-actin (42 kDa; ab3280; 1:8,000) (Abcam Biotechnology, Cambridge, UK), anti-cyclin D1 (36 kDa; sc-56302; 1:1,000) (Santa Cruz Biotechnology) or anti-PGEA1 (17 kDa; NBP1-46303; 1:2,000) (Novus Biologicals). The blots were then incubated with anti-mouse or anti-rabbit immunoglobulin G $(1: 5,000)$. Protein expression was visualized using enhanced chemiluminescence system (ECL; Bio-Rad). $\beta$-actin served as an internal standard. Using Quantity One software (Bio-Rad), relative protein levels were quantified by densitometry.

Luciferase reporter gene assay. Wnt signaling was assessed using the well-described TOPflash assay (24). Briefly, $5 \times 10^{4}$ Hep-2 cells per well grown for $24 \mathrm{~h}$ in 24 -well plates were transiently transfected with $100 \mathrm{ng} /$ well of TOPflash or FOPflash reporter gene plasmid together with $50 \mathrm{ng} /$ well of Renilla luciferase control plasmid pREP7-RLuc as an internal control reporter using TurboFect ${ }^{\mathrm{TM}}$ (Fermentas) at a ratio of 1:2.5 (weight DNA:volume TurboFect ${ }^{\mathrm{TM}}$ ). For cotransfection, 50, 10 and $200 \mathrm{ng}$ recombinant expression plasmid plv-cs2.0-Cby were used, respectively. Thirty-six hours post transfection, cells were washed and lysed in passive lysis buffer (Promega) and the transfection efficiency was normalized to the paired Renilla luciferase activity by using the Dual Luciferase Reporter assay system (Promega Corp., Madison, WI, USA) using a fluorescence microplate reader (FLUOstar Optima, Offenburg, Germany) according to the manufacturer's instructions. The degree of cell confluence refers to the time of transfection with TOPflash or FOPflash. 
MTT cytotoxicity assay. MTT cytotoxicity assays were used to assess cell viability as a marker of proliferation. Cells $\left(5 \times 10^{2}\right)$ (control, LV-GFP and LV-Cby) were seeded into each well of a 96-well plate. MTT assay was performed at 24, 48, 72, 96, 120 and $144 \mathrm{~h}$. Twenty microliters of $5 \mathrm{mg} / \mathrm{ml} \mathrm{MTT}$ was added to each well and incubated for $4 \mathrm{~h}$ at $37^{\circ} \mathrm{C}$. The medium was removed and $150 \mu \mathrm{l}$ dimethyl sulfoxide (DMSO) was added into each well and the plate was shaken for $10 \mathrm{~min}$ to dissolve the crystals. After shaking and dissolving, the $A$ values at the wavelength of 570 and $630 \mathrm{~nm}$ were determined by using enzyme-labeled instrument (Bio-Rad). The growth curves of Hep-2 cells were plotted by growth time as the abscissa and valve of OD570-OD630 as the vertical coordinates.

Colony formation assay. To assess colony formation of three cell groups, 500 cells/plate (control, LV-GFP and LV-Cby) were seeded into three $3.5 \mathrm{~cm}^{2}$ plates. Cells were maintained at $37^{\circ} \mathrm{C}$ in an incubator containing $5 \% \mathrm{CO}_{2}$. After incubation, the medium was renewed and the plates were incubated for 10 days under the same culture conditions. The cells were washed twice with ice-cold phosphate-buffered saline (PBS) and fixed with methanol for $20 \mathrm{~min}$ in room temperature, followed by staining with Giemsa (0.4 g Giemsa, $25 \mathrm{ml}$ methanol, $25 \mathrm{ml}$ glycerol) for $20 \mathrm{~min}$ at room temperature. Colonies containing $>25$ cells originating from single cells were counted under an inverted microscope (Olympus CK40, Tokyo, Japan).

Cell cycle assay. Cell cycle analysis was performed following propidium iodide (PI) staining. The three cell groups (control, LV-GFP and LV-Cby) were seeded into three $6 \mathrm{~cm}$ flasks and incubated at $37^{\circ} \mathrm{C} 5 \% \mathrm{CO}_{2}$ for $48 \mathrm{~h}$. These cells were collected by trypsinization, centrifuged at $1,000 \mathrm{x} \mathrm{g}$ for $5 \mathrm{~min}$, washed twice in cold PBS and fixed overnight in $70 \%$ ethanol at $4^{\circ} \mathrm{C}$ and then treated with $5 \mu \mathrm{l}$ RNase A $(10 \mathrm{mg} / \mathrm{ml})$ in $0.4 \mathrm{ml}$ PBS at $37^{\circ} \mathrm{C}$ for $1 \mathrm{~h}$. Cell nuclei were stained with $50 \mu \mathrm{PI}(1 \mathrm{mg} / \mathrm{ml})$ at $37^{\circ} \mathrm{C}$ for $30 \mathrm{~min}$. The cells $\left(5 \times 10^{5}\right)$ were then analyzed for their DNA content using a FACSCalibur flow cytometer. All data acquisition and analyses were performed with BectonDickinson FACSCalibur flow cytometer.

Cell apoptosis assay. Cell apoptosis analysis was stained using the terminal deoxynucleotidyl transferase (TdT) dUTP nick end labelling (TUNEL) method using an In Situ Cell Death Detection kit, AP (Roche, Basel, Switzerland) according to the manufacturer's instructions. The three groups (control, LV-GFP and LV-Cby) were collected by trypsinization, centrifuged at $1,000 \mathrm{x}$ g for $5 \mathrm{~min}$, washed twice in cold PBS and fixed in $70 \%$ cold ethanol for $20 \mathrm{~min}$. Fifty micrograms fixed cells were added to the slides and dried at room temperature for TUNEL assay. Air-dried cell slides were fixed with $4 \%$ paraformaldehyde $(\mathrm{pH} 7.4)$ for $1 \mathrm{~h}$ at room temperature and incubated in permeabilization solution $(0.1 \%$ Triton $\mathrm{X}-100$ in $0.1 \%$ sodium citrate). After rinsing twice with PBS, $50 \mu 1$ freshly prepared TUNEL reaction mixture containing $10 \%$ TdT solution (vial 1) and $90 \%$ fluorescein-dUTP one (vial 2) was added to the samples for $1 \mathrm{~h}$ at $37^{\circ} \mathrm{C}$ in a humidified atmosphere in the dark. After rinsing thrice with PBS, the samples were analyzed in a drop of PBS under fluorescence microscope using an excitation or detection wavelength in the range of 450-500 or 515-565 nm (green), respectively, and then incubated with $50 \mu \mathrm{l}$ converter-AP (vial 3) for $30 \mathrm{~min}$ at $37^{\circ} \mathrm{C}$. Detection was performed with BCIP/NBT and slides were counterstained with nuclear fast red, followed by analysis under light microscope. Negative control samples underwent the same process with omission of the TdT enzyme. Positive control samples were pretreated with $100 \mathrm{U} / \mathrm{ml}$ DNase I for $10 \mathrm{~min}$ at $15-25^{\circ} \mathrm{C}$ to induce DNA strand degradation before the labelling procedure.

Statistical analysis. Statistical analyses were performed using SPSS 17.0 software package (SPSS, Chicago, USA). Fisher's exact test was used to analyze Cby protein expression between tumor and normal tissues and to assess protein expressed differences in different gender, ages, clinical staging and differentiated degree. Data are presented as positive (\%). All experiments in Hep-2 cells were repeated at least three times with independent cultures. The results from these experiments were transformed into measurement data and are presented as mean \pm standard error (mean $\pm \mathrm{SE}$ ). Differences between groups were analyzed for statistical significance using one-way analysis of variance (ANOVA). Results with $\mathrm{P}<0.05$ were considered statistically significant.

\section{Results}

Cby expression is downregulated in human LSCC samples. We first assessed the difference of expression level of Cby protein between 36 LSCC samples and their adjacent normal laryngeal mucosa by immunochemistry. Cby protein expression was seldom observed in LSCC tissues. In contrast, the majority of normal laryngeal mucosa sections exhibited various levels of expression. The subcellular localization of Cby protein was shown to be mainly in the nucleus and slightly in the cytoplasm in normal laryngeal mucosa (Fig. 1A). Comparing the LSCC tissues with the corresponding adjacent normal laryngeal mucosa from the same patient from the 36 cases, the downregulated expression of Cby protein in tumor was detected in 24/36 (66.67\%) samples. The difference was statistically significant $(\mathrm{P}<0.05$, Fig. $1 \mathrm{~B})$. To determine the relationship between protein aberrant expression and clinicopathological characteristics, differences were analyzed using the expression level of Cby protein in tumor samples. There was no correlation with gender (male/female), age ( $<61$ years/ $\geq 61$ years), clinical staging (I/II/III/IV) and tumor differentiated degree (highly/moderately/poorly) (all $\mathrm{P}>0.05$, Fig. 1C). Taken together, these results indicate that Cby may play a role in the early stage of LSCC carcinogenesis.

Enforced expression of Cby in Hep-2 cells inhibits Wnt signaling. Cby has been demonstrated to be a negative regulator of $\beta$-catenin in drosophila. Its role in mammalian cells, especially in tumor cells, remains largely obscure. To address this issue, we stably overexpressed Cby in laryngeal carcinoma Hep-2 cells with a lentiviral eukaryotic expression vector plv-cs $2.0-\mathrm{Cby}_{\text {viral }}$. RT-PCR results showed that no significant difference of Cby mRNA levels between the control group (without treatment) and the LV-GFP group (infected with plv-cs2.0-GFP ${ }_{\text {viral }}$ ), while a significant upregulation was observed in the plv-cs2.0-Cby viral -infected group. RT-PCR analysis revealed that Cby mRNA was expressed 
A
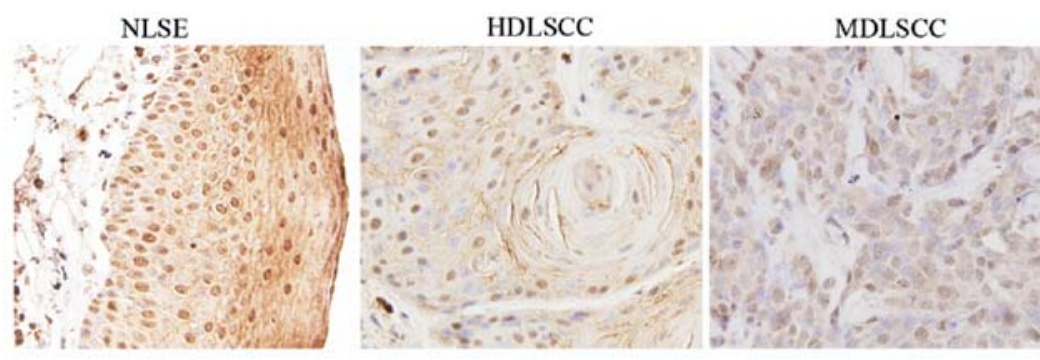

PDLSCC

B

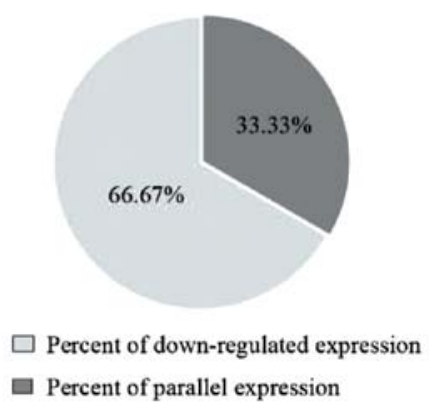

C

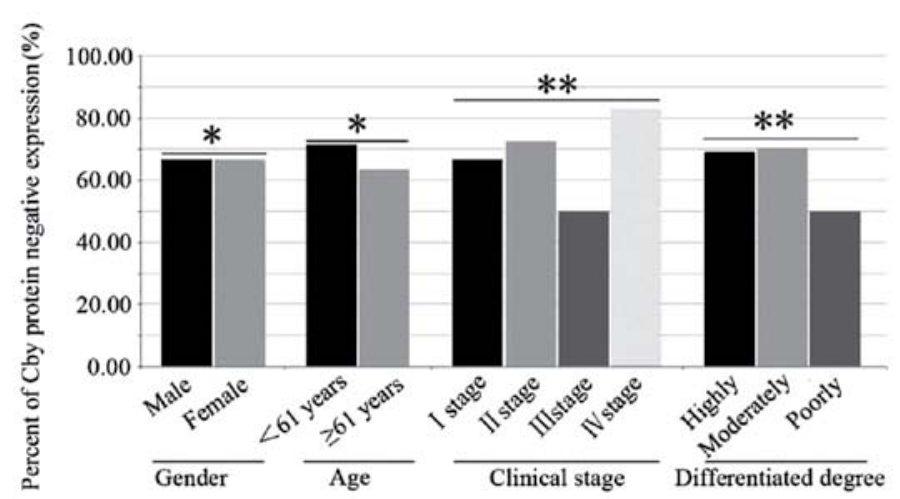

Figure 1. Chibby (Cby) expression levels in laryngeal squamous cell carcinoma (LSCC) and corresponding normal laryngeal mucosa samples. (A) Cby protein expression levels in LSCC samples of different differentiated degree and normal laryngeal mucosa samples, as detected by immunochemistry. NLSE, normal laryngeal squamous epithelium; HDLSCC, highly differentiated LSCC; MDLSCC, moderately differentiated LSCC; PDLSCC, poorly differentiated LSCC; HE staining, hematoxylin-eosin staining. Strong Cby expression was detected in NLSE, with weak or no Cby protein expression in HDLSCC, MDLSCC and PDLSCC (original magnification, $\mathrm{x} 400$ ). (B) Percent of Cby protein reduced expression. Comparing LSCC tissues with corresponding adjacent normal laryngeal mucosa from the same patient, the downregulated expression of Cby protein in tumor was detected in 24/36 (66.67\%) samples. (C) The relationship between protein aberrant expression and clinicopathological characteristics in the tumor samples. There was no significant expression difference in any group of tumors stratified according to gender, age, clinical staging and tumor differentiated degree. "P $>0.05$ between the group of gender or age (determined using the Fisher's exact test in $2 \times 2$ table). ${ }^{* *} \mathrm{P}>0.05$ among the group of clinical staging or tumor differentiated degree (determined using the Fisher's exact test in $\mathrm{RxC}$ table).

327.79-fold in the plv-cs2.0-Cby viral -infected Hep-2 cells (Fig. 2A). Furthermore, Cby protein expression was determined by western blot analysis and verified the RT-PCR results (Fig. 2B). These results indicate that the expressed level of Cby was effectively upregulated in the Hep-2 cells with plv-cs2.0-Cby viral $_{\text {. }}$.

Next, we detected the expression levels of $\beta$-catenin, as well as c-myc and cyclin D1, the two known target genes of Wnt signaling by RT-PCR and western blot analysis. The expression of $\beta$-catenin at both mRNA and protein levels showed no significant changes among the three groups $(\mathrm{P}>0.05)$ (Fig. 2C and D). In addition, the expressed level of c-myc was also very similar among the three groups $(\mathrm{P}>0.05)$ (Fig. 2C and D). However, compared to the control and plv-cs2.0 groups, cyclin D1 expression level in the LV-Cby group was strongly downregulated at both the mRNA and protein levels ( $\mathrm{P}>0.05)$ (Fig. 2C and $\mathrm{D})$. These results suggest that overexpression of Cby in laryngeal carcinoma Hep-2 cells selectively inhibited the expression of Wnt target gene cyclin D1 but did not affect the expression of $\beta$-catenin.

To further examine the molecular mechanism of Cby in regulating $W n t / \beta$-catenin signaling pathway activity, the TCF/LEF luciferase reporter TOPflash/FOPflash assay was used when co-transfected with plv-cs2.0-Cby plasmids in Hep-2 cells. The TOPflash activity was significantly induced in Hep-2 cells, which is indicative of the existence of activated Wnt signaling in the cells. However, the TOPflash activity was repressed by Cby in a dose-dependent manner
$(\mathrm{P}<0.05)$ (Fig. 2E). As a control, the FOPflash activity was not altered ( $\mathrm{P}>0.05)$ (Fig. 2E).

Enforced expression of Cby in Hep-2 cells inhibits cell proliferation. One of the most important roles for Wnt signaling is improving cell proliferation. To investigate whether overexpression of Cby has inhibitory effects on proliferation in Hep-2 cells, the MTT assay and colony formation assay were performed. Cell viability detected by MTT assay displayed no difference between the control $(1.819 \pm 0.118)$ and the LV-GFP group (1.648 \pm 0.143$)(P>0.05)$, but a significant decrease was observed in the LV-Cby group $(0.910 \pm 0.048)$ $(\mathrm{P}<0.05)$ (Fig. 3A). Next, we detected whether Cby inhibited Wnt signaling-mediated cell proliferation. Hep-2 cells were infected with LV-GFP or LV-GFP+LV- $\beta$-catenin. As anticipated, $\beta$-catenin promoted cell viability of Hep-2 cells by MTT assay $(2.125 \pm 0.222$ vs. $1.428 \pm 0.192, \mathrm{P}<0.05)$. However, when co-infected with LV-Cby, $\beta$-catenin no longer enhanced the cell viability (Fig. 3B). To further determine the anti-proliferative effect in vitro, the ability of Cby to suppress colony formation was examined. Compared to the control group, the ability of colony formation is similar to that in the LV-GFP group ( $\mathrm{P}>0.05)$; however, suppression was clearly observed in the LV-Cby group $(\mathrm{P}<0.05)$. When the number of colonies was quantified, the percentage of colony formation was $31.67 \pm 3.33,29.00 \pm 2.67$ and $11.33 \pm 4.67 \%$, respectively (Fig. 3C). Consistent with the MTT assay, Cby was observed to inhibit $\beta$-catenin-promoted colony formation (Fig. 3D) as 
A

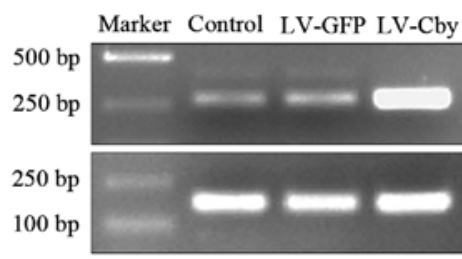

Cby

18sRNA

$\mathbf{B}$

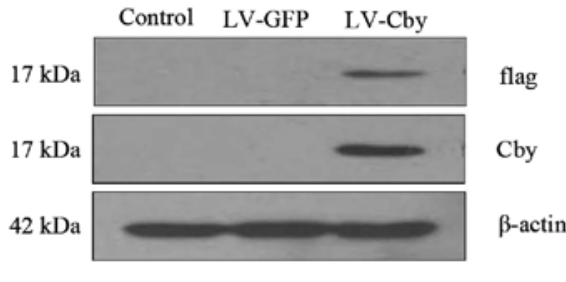

C

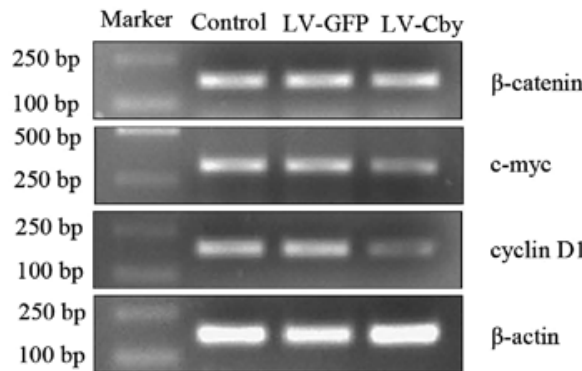

D

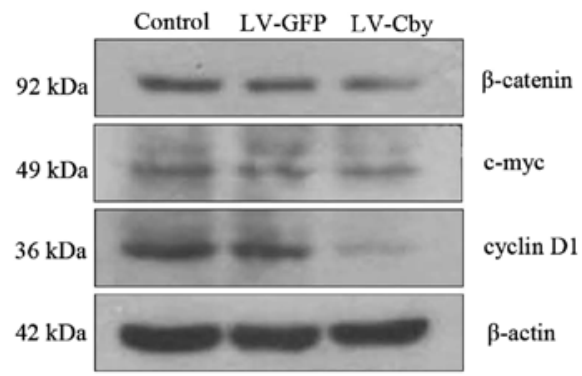

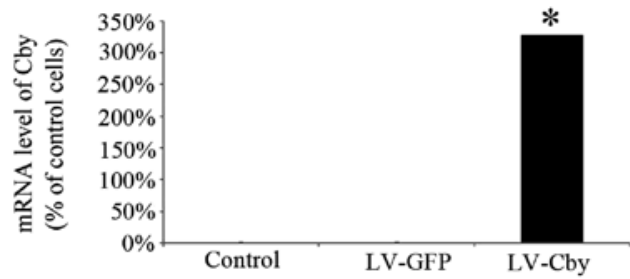
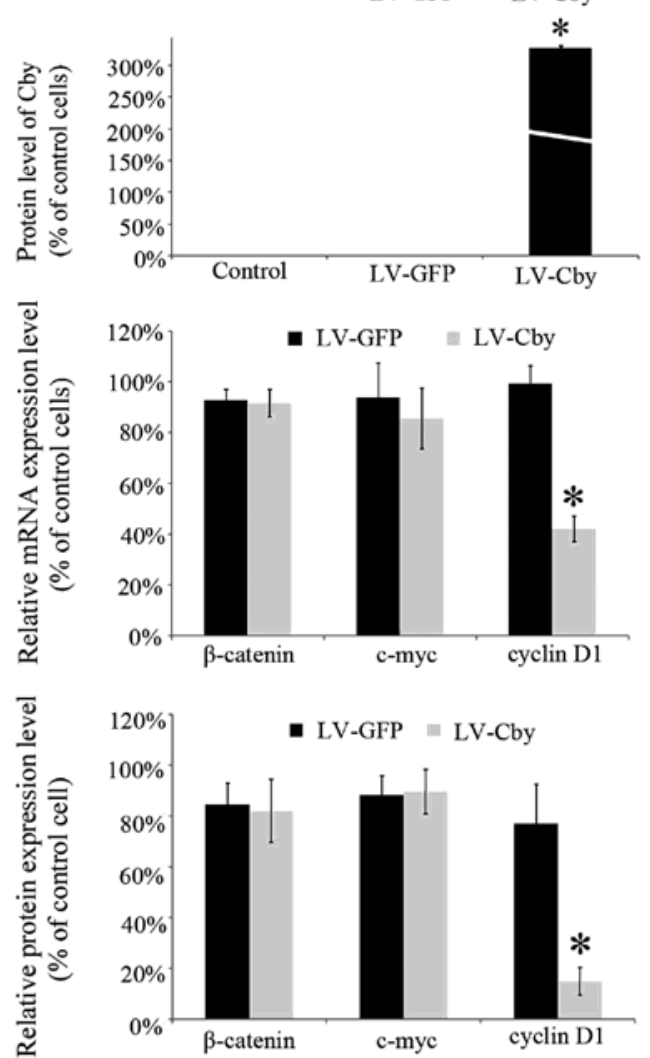

$\mathbf{E}$

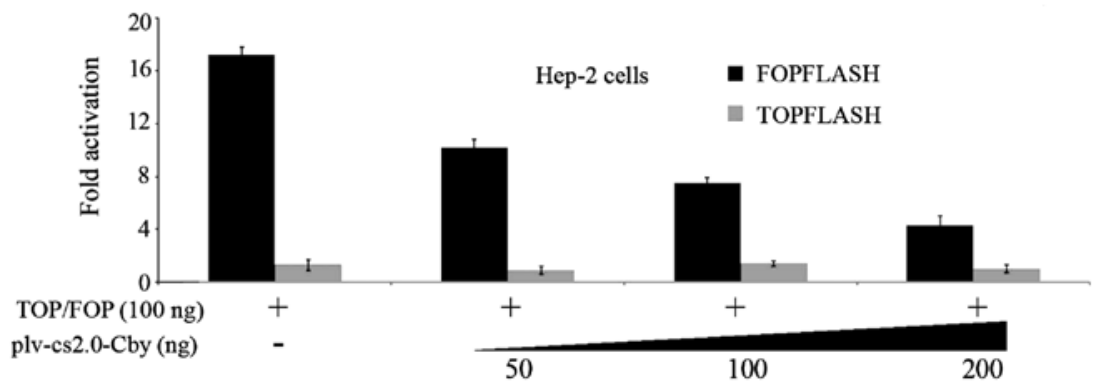

Figure 2. Enforced expression of Chibby (Cby) in Hep-2 cells inhibits Wnt signaling. The three cell groups (control group without treatment, LV-GFP group infected with plv-cs2.0-GFP ${ }_{\text {viral }}$ and LV-Cby group infected with plv-cs $2.0-\mathrm{Cby}_{\text {viral }}$ ) were cultured in three $3.5 \mathrm{~cm}^{2}$ plates and harvested for $48 \mathrm{~h}$. (A) Representative RT-PCR results of Cby and $\beta$-actin mRNA expression level in these groups, with 18sRNA expression level as an internal standard. (B) Representative western blot results of Cby and $\beta$-actin protein expression level in these groups, with $\beta$-actin protein expression level as an internal standard. (C) RT-PCR analysis of the mRNA expression of $\beta$-catenin, c-myc and cyclin D1 in the three groups, with 18sRNA expression level as an internal standard. (D) Representative western blot results of $\beta$-catenin, c-myc and cyclin D1 protein expression level in these groups. $\beta$-actin was used as a loading control. (E) Activity of Wnt/ $\beta$-catenin signaling pathway after plv-cs2.0-Cby transfection by the TCF/LEF luciferase reporter gene assay. Hep- 2 cells $\left(5 \times 10^{4}\right)$ per well grown for $24 \mathrm{~h}$ in 24 -well plates were transiently transfected with TOPflash/FOPflash reporter gene plasmid and plv-cs2.0-Cby plasmid and relative luciferase activity was determined after culturing for $36 \mathrm{~h}$. Data represent mean $\pm \mathrm{SE}$ from three independent analyses. " $\mathrm{P}<0.01$ vs. LV-GFP group.

indicated by the percentage of colony formation $(36.67 \pm 5.00$, $75.00 \pm 8.33$ and $45.00 \pm 3.33 \%$, respectively). Taken together, these data demonstrate that enforced expression of Cby inhibits proliferation of Hep-2 cells and this function appears to be Wnt signaling-dependent.

Enforced expression of Cby in Hep-2 cells induces G1-phase arrest. To further confirm the growth inhibition on Hep-2 cells induced by Cby overexpression, the cell cycle assay was performed. The three groups (control, LV-GFP and LV-Cby) were cultured for $48 \mathrm{~h}$, stained with PI and measured using flow cytometry. Overexpression of Cby resulted in arrested G1 phase, as indicated by an increase in the percentage of cells in G1 $(70.10 \pm 1.25 \%)$ compared with those in the control $(52.40 \pm 4.31 \%)$ and LV-GFP $(53.40 \pm 4.09 \%)$ cells, respectively $(\mathrm{P}<0.05)$ (Fig. 4). In addition, the G1 cell increase was 
A

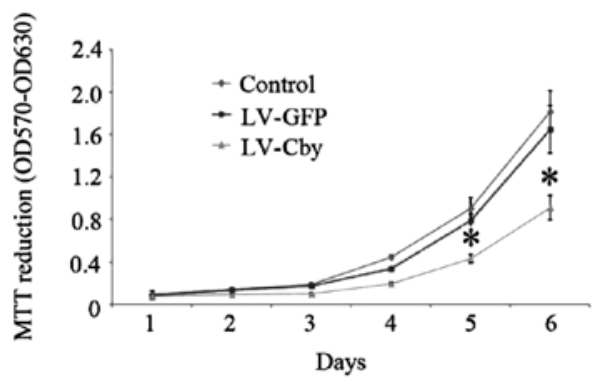

C
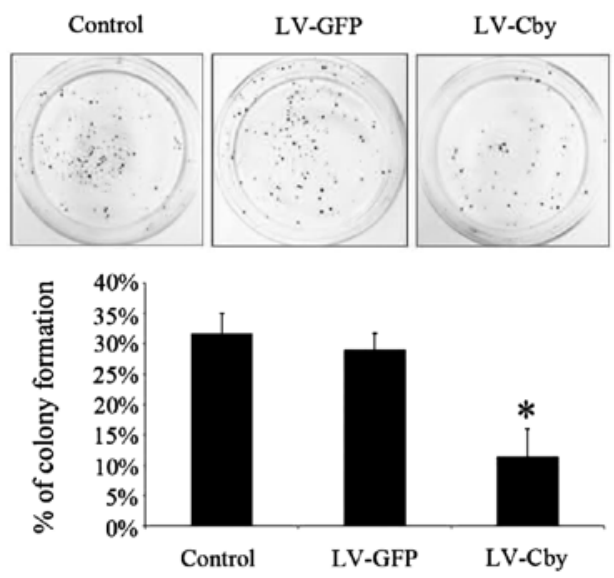

B

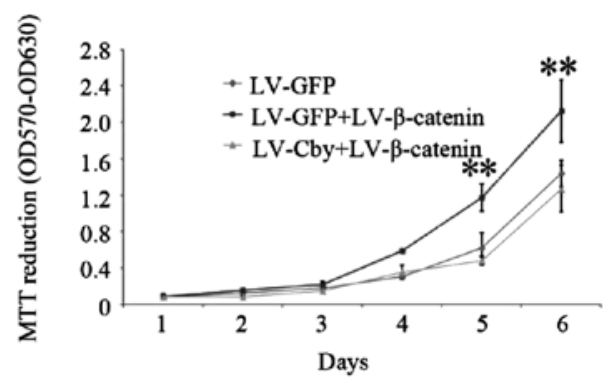

D
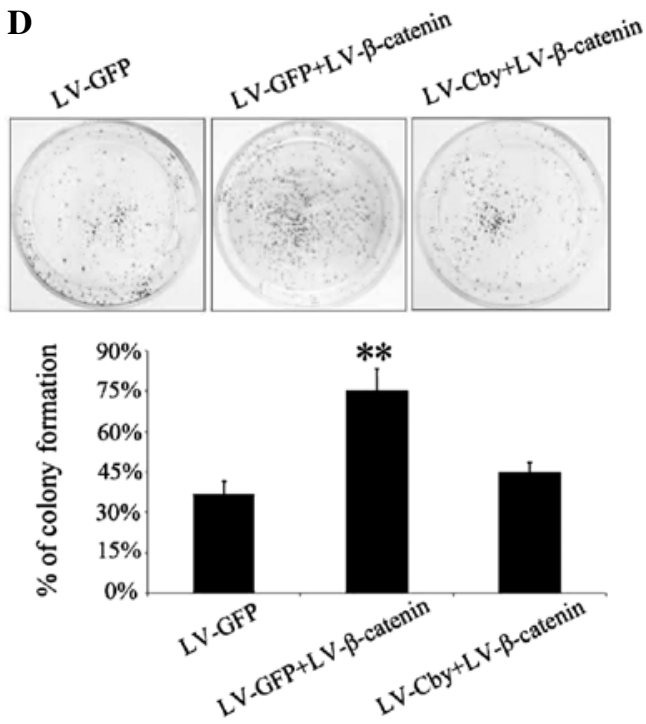

Figure 3. Effect of Chibby (Cby) suppression on Hep-2 cell proliferation. (A) Hep-2 cells (5x10²) (control, LV-GFP and LV-Cby group) were seeded into each well of a 96-well plate. The cell viability of these groups was determined by MTT assay performed at 24, 48, 72, 96, 120 and $144 \mathrm{~h}$ after seeding. (B) Hep-2 cells $\left(5 \times 10^{2}\right)(\mathrm{LV}-\mathrm{GFP}, \mathrm{LV}-\mathrm{GFP}+\mathrm{LV}-\beta$-catenin and LV-Cby+LV- $\beta$-catenin group) were seeded into each well of a 96 -well plate. The cell viability of these groups was determined by MTT assay performed at 24, 48, 72, 96, 120 and $144 \mathrm{~h}$ after seeding. (C) Hep-2 cells (5x102) (control, LV-GFP and LV-Cby group) were seeded into three $3.5 \mathrm{~cm}^{2}$ plates and cultured for 10 days, respectively. The cells were fixed with methanol and stained with Giemsa. The colonies as the percentage of cell viability were quantified under an inverted microscope and represent mean \pm SE from three independent experiments. (D) Hep- 2 cells $\left(5 \times 10^{2}\right)$ (LV-GFP, LV-GFP+LV- $\beta$-catenin and LV-Cby+LV- $\beta$-catenin group) were seeded into three $3.5 \mathrm{~cm}^{2}$ plates and cultured for 10 days, respectively. The cells were fixed with methanol and stained with Giemsa. The colonies as the percentage of cell viability were quantified under an inverted microscope. Data represent mean $\pm \mathrm{SE}$ from three independent experiments. ${ }^{*} \mathrm{P}<0.05$ vs. LV-GFP group. ${ }^{* *} \mathrm{P}<0.05$ vs. LV-GFP+LV- $\beta$-catenin group.

A
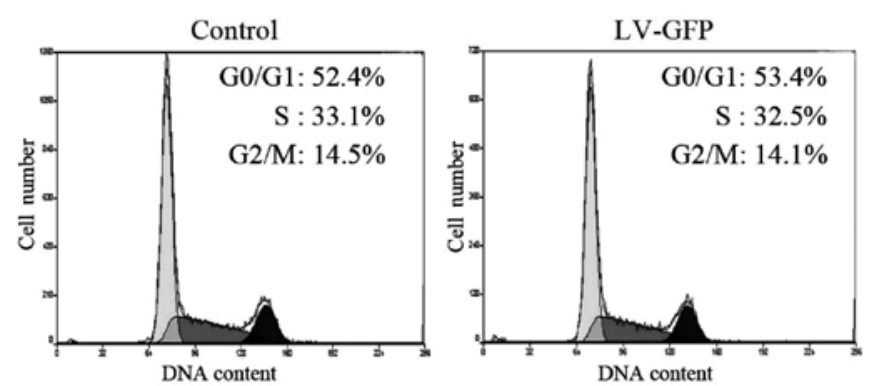

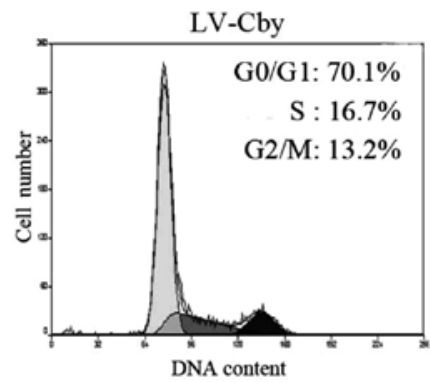

DNA content

B

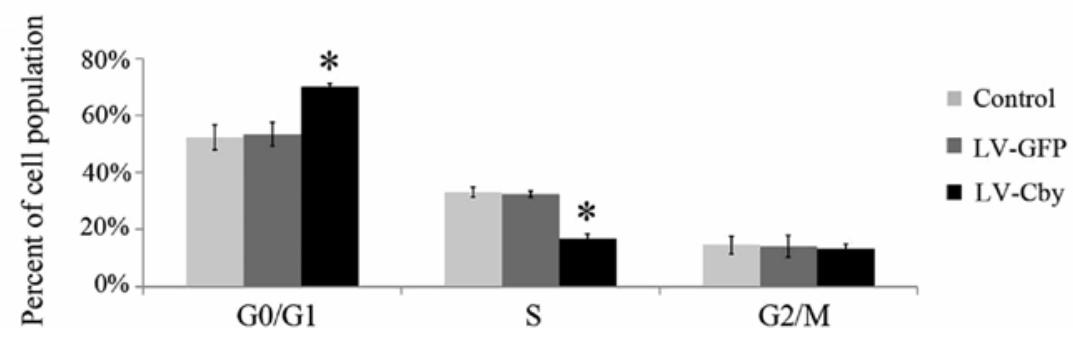

Figure 4. G1-phase arrest in Hep-2 cells induced by overexpression of Chibby (Cby). (A) The three groups of cells (control, LV-GFP and LV-Cby) were collected and stained with PI, followed by analysis with flow cytometry. Cellular DNA histograms were analyzed by ModiFitLT V3.0. (B) Percentage of cells in $\mathrm{G} 1, \mathrm{~S}$ and $\mathrm{G} 2 / \mathrm{M}$ phase were calculated using cell-fit computer software and are represented under the histograms. Data represent mean \pm SE from three independent experiments. "P<0.05 vs. LV-GFP group. 
A

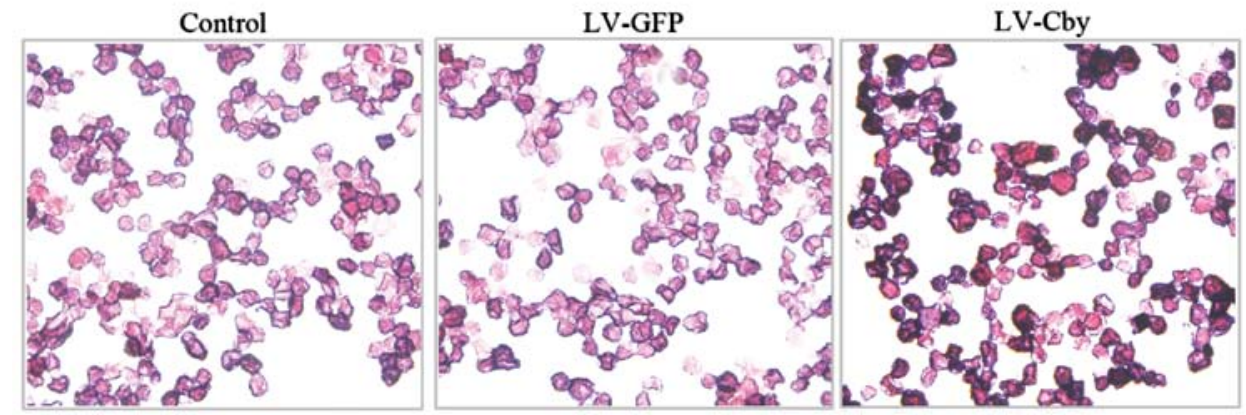

B

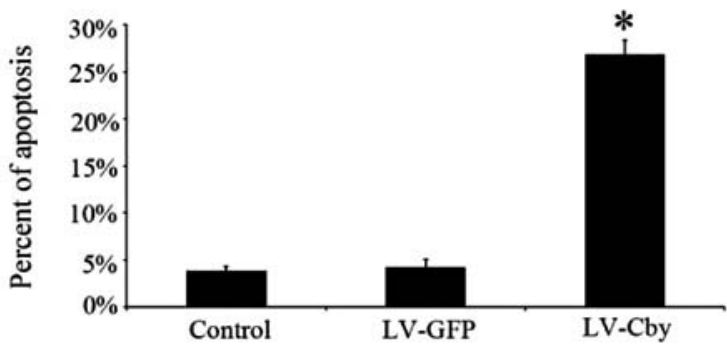

Figure 5. Effect of apoptosis in Hep-2 cells induced by overexpression of Chibby (Cby). (A) The three groups of cells (control, LV-GFP and LV-Cby) were smeared on three slides, treated with TUNEL reaction mixture and subsequently stained with BCIP/NBT and counterstained with nuclear fast red. The positive signaling was viewed under light microscope (deep red). (B) The percentage of apoptotic rate relative to control group. Data represent mean \pm SE from three independent experiments. ${ }^{\mathrm{P}}<0.01$ vs. LV-GFP group.

accompanied by a decrease in the proportion in $\mathrm{S}$ phase. Percentage of control and LV-GFP group cells in S phase was $33.10 \pm 1.77$ and $32.50 \pm 1.13 \%$ of total cells, respectively, while the LV-Cby group had a lower proportion of S-phase cells $(16.71 \pm 1.76 \%)(\mathrm{P}<0.05)$ (Fig. 4). No differences were observed between the control and LV-GFP groups ( $\mathrm{P}>0.05)$ (Fig. 4). The results suggest that Cby causes an accumulation in $\mathrm{G} 0 / \mathrm{G} 1$ phase and a reduction in $\mathrm{S}$ phase in laryngeal carcinoma Hep-2 cells.

Enforced expression of Cby in Hep-2 cells causes apoptosis. To investigate whether Cby overexpression-mediated growth inhibition is also associated with apoptosis of Hep-2 cells, the TUNEL assay was performed. The three cell groups (control, LV-GFP and LV-Cby) were smeared on slides and treated with TUNEL reaction mixture and analyzed under a microscope. The TUNEL staining showed that apoptotic cells in the plv-cs2.0-Cby ${ }_{\text {viral }}$ group were significantly increased when compared with the 2 control groups (Fig. 5A). The folds of apoptotic rate increased from $4.27 \pm 0.81$ to $26.89 \pm 1.46 \%$ (Fig. 5B). The results suggest that the enforced expression of Cby induced apoptosis of laryngeal carcinoma Hep-2 cells.

\section{Discussion}

LSCC is a common poorly differentiated squamous tumor of the head and neck and the currently available combined therapies offer only limited benefits for patients, especially for functional recovery of larynx and overall 5-year survival. The approaches that alter or modify some important genes or their expression products have become a research hotspot in the biological treatment of LSCC. Therefore, there is an urgent need to further explore the molecular pathogenesis of LSCC. Many studies have shown that tumor formation is closely related to abnormal regulation of many signaling pathways including Wnt/ $\beta$-catenin signaling which plays diverse roles in embryonic development, stem cell self-renewal and adult homeostasis $(3,27)$. However, there is very little knowledge regarding $W n t / \beta$-catenin signaling cascade genes in LSCC, although several reports have shown that $\beta$-catenin, which is closely related to differentiation, clinical stage, metastasis and prognosis of laryngeal carcinoma, is upregulated (14-16) and the $A P C$ gene which plays an important role in LSCC development is frequently lost $(17,18)$. Hence, our study investigated the question of whether the expression of Cby, a newly found antagonist of the Wnt/ $\beta$-catenin pathway, is altered in LSCC tissues, and, if so, whether restoration of Cby expression in laryngeal carcinoma cell line could affect the biological behavior.

In the present study, we detected the expression level of Cby in LSCC tumor tissues by immunochemistry, and further analyzed the correlation with clinicopathological features of LSCC patients. Compared with corresponding adjacent normal laryngeal mucosa, the Cby expression level in LSCC tumor tissues was downregulated (Fig. 1). Consistent with our study, downregulation of Cby was shown in thyroid cancer, colon carcinoma cell lines and pediatric ependymomas (22-24). However, the cause for Cby downregulation in tumors remains unclear. No mutation of Cby gene was detected in colorectal cancer and pediatric ependymomas $(23,24)$, but loss of heterozygosity involving the $C 22 \operatorname{orf} 2$ region and methylation of C22orf2 promoter was determined in some colorectal cancer patients and pediatric ependymoma samples (23). Due to different histological types, the cause for downregulation of Cby in LSCC tissues could be explained by these phenomena and require further investigation. It is noteworthy that the Cby expression reduced tumor sample protein level more than mRNA level, probably since some unknown factors inhibit the Cby protein translation or stabilization. On the other 
hand, no correlation between the expression of Cby in tumor tissues and gender (male/female), age ( $<61$ years/ $\geq 61$ years), clinical staging (I/II/III/IV) and tumor differentiated degree (highly/moderately/poorly) was found in our experiments, which suggests that Cby may play a role in the early stage of LSCC carcinogenesis.

It has been suggested that Cby blocks the Wnt/ $\beta$-catenin signaling pathway by suppressing the activity of $\beta$-catenin, a protein interaction that is essential for the transcriptional activation of Wnt target genes (19-21). In addition to regulating the export of $\beta$-catenin from the nucleus, Cby mainly plays an antagonistic role in Wnt signaling by inhibiting the binding of $\beta$-catenin to TCF/LEF family proteins $(19-21,28)$. Whether regulating intracellular distribution of $\beta$-catenin or inhibiting its binding to TCF/LEF transcription factors, both mechanisms appear to be necessary for Cby to achieve full repression of $\beta$-catenin transcriptional activity (20). Thus, we assessed the effects of Cby on repression of $\beta$-catenin activity which led to alteration in the biological behaviors in Hep-2 cells. To confirm the role of Cby on the $\beta$-catenin-dependent pathway, we observed the $\mathrm{Wnt} / \beta$-catenin signaling pathway transcription activity by TCF/LEF luciferase reporter assay. We found that the TOPflash activity in laryngeal carcinoma Hep-2 cells was repressed by Cby in a dose-dependent manner, which is suggestive of its role in Wnt signaling (Fig. 2E).

We examined the Wnt target genes whose expression is affected by Cby and alter the biological behaviors of Hep-2 cells. As a transcription factor, $\beta$-catenin induces the expression of a series of downstream target genes to promote tumor growth or progression. C-myc and cyclin D1 are two important target genes of $\beta$-catenin (11-13). C-myc is a nuclear phosphoprotein that functions as a transcription factor stimulating cell-cycle progression. $\mathrm{C}$-myc promotes the transition from $\mathrm{G} 1$ to the $\mathrm{S}$ phase under the stimulation of many signals. A large number of cells in G0 phase early entry into cell cycle, which cause cell cycle disorder and formation of tumor $(29,30)$. Studies have shown that there is abnormal expression of c-myc in laryngeal carcinoma (31-33). Cyclin D1 as another important positive regulator has a rate-limiting role in G1-S phase transition. Both transgenic mouse models and clinical studies indicate a pivotal role for cyclin D1 in normal and malignant cell growth (34). Studies have also revealed the close relationship between expression of cyclin D1 and laryngeal carcinoma $(35,36)$. These reports indicate that c-myc and cyclin D1 are all involved in LSCC. In the present study, we detected a selective inhibition of Wnt target gene cyclin D1 but not c-myc (Fig. 2C and D). We reasoned that there is endogenous mutation(s) on c-myc in the Hep-2 cells, which leads to the constitutive expression of this gene. Our results provide a good example of Cby in suppressing Wnt signaling in tumor cells.

The expression of Cby in LSCC is downregulated, which suggests that Cby may function as a potential tumor suppressor in LSCC. To test our hypothesis, lentiviral eukaryotic expression vector plv-cs2.0-Cby viral $_{\text {was }}$ constructed and stably expressed in laryngeal carcinoma cell line Hep-2. Tests for re-expression of Cby in tumor cells were followed by functional assays including proliferation, cell cycle and apoptosis. The significant inhibitory effect of Cby on tumor cell proliferation, the G1 phase arrest and the increased apoptotic cells all refer to the inhibition of Wnt signaling, which is consistent with the molecular mechanism for Cby in regulating Wnt $/ \beta$ catenin activity (Figs. 3-5).

In conclusion, Cby expression is downregulated in LSCC, but there is no significant correlation between Cby expression and the clinicopathological features of LSCC. Enforced expression of Cby effectively suppresses laryngeal carcinoma cell growth and promotes apoptosis. Cby exerts its function by inhibiting Wnt signaling. A better understanding of the mechanisms of Cby gene inactivation in LSCC may provide potential novel therapeutic targets for human laryngeal carcinoma.

\section{Acknowledgements}

The authors are grateful to the State Key Laboratory of Cellular Stress Biology at Xiamen University for use of the facilities. We would also like to thank Dr Liu Qing-Feng for the important collaboration in the immunohistochemistry experiments, Mr. Gui Long-Xing for the assistance in lentiviral vector preparation, Dr Cai Wang-Yu for the technical assistance with luciferase reporter gene assay and MTT cytotoxicity assay. This study was supported by grants from the Foundation of Huzhou Bureau of Science and Technology (No. 2013GY25).

\section{References}

1. Mojica-Manosa P, Reidy J, Wilson K and Douglas W: Larynx squamous cell carcinoma: concepts and future directions. Surg Oncol Clin N Am 13: 99-112, 2004.

2. Almadori G, Bussu F, Cadoni G, Galli J, Paludetti G and Maurizi M: Molecular markers in laryngeal squamous cell carcinoma: towards an integrated clinicobiological approach. Eur J Cancer 41: 683-693, 2005.

3. Klaus A and Birchmeier W: Wnt signalling and its impact on development and cancer. Nat Rev Cancer 8: 387-398, 2008.

4. Clevers H: Wnt// $/$-catenin signaling in development and disease. Cell 127: 469-480, 2006.

5. Brown AM: Wnt signaling in breast cancer: have we come full circle? Breast Cancer Res 3: 351-355, 2001.

6. Lustig B and Behrens J: The Wnt signaling pathway and its role in tumor development. J Cancer Res Clin Oncol 129: 199-221, 2003.

7. Polakis P: Wnt signaling and cancer. Genes Dev 14: 1837-1851, 2000.

8. Taipale $\mathrm{J}$ and Beachy PA: The Hedgehog and Wnt signalling pathways in cancer. Nature 411: 349-354, 2001.

9. Logan CY and Nusse R: The Wnt signaling pathway in development and disease. Annu Rev Cell Dev Biol 20: 781-810, 2004.

10. Kimelman D and Xu W: Beta-catenin destruction complex: insights and questions from a structural perspective. Oncogene 25: 7482-7491, 2006.

11. Tetsu $\mathrm{O}$ and McCormick F: B-catenin regulates expression of cyclin D1 in colon carcinoma cells. Nature 398: 422-426, 1999.

12. Shtutman M, Zhurinsky J, Simcha I, et al: The cyclin D1 gene is a target of the $\beta$-catenin/LEF-1 pathway. Proc Natl Acad Sci USA 96: 5522-5527, 1999.

13. He TC, Sparks AB, Rago C, et al: Identification of c-MYC as a target of the APC pathway. Science 281: 1509-1512, 1998.

14. Pietruszewska W, Kobos J and Gryczyński M: Expression of beta-catenin protein in laryngeal squamous-cell carcinoma. Otolaryngol Pol 58: 949-956, 2004 (In Polish).

15. Si WF, Sun W, Liu H, Liu J, Sun Y and Chen Z: Expression and clinical significance of E-cadherin and beta-catenin proteins in human laryngeal cancer. Lin Chung Er Bi Yan Hou Tou Jing Wai Ke Za Zhi 22: 459-461, 2008 (In Chinese).

16. Goulioumis AK, Varakis J, Goumas $\mathrm{P}$ and Papadaki $\mathrm{H}$ : Differential $\beta$-catenin expression between glottic and supraglottic laryngeal carcinoma. Eur Arch Otorhinolaryngol 267: 1573-1578, 2010.

17. Sanz Ortega J, Valor C, Saez MC, et al: 3p21, 5q21, 9p21 and $17 \mathrm{p} 13$ allelic deletions accumulate in the dysplastic spectrum of laryngeal carcinogenesis and precede malignant transformation. Histol Histopathol 18: 1053-1057, 2003. 
18. Pećina-Šlaus N, Kljaić $M$ and Nikuševa-Martić T: Loss of heterozygosity of APC and $\mathrm{CDH} 1$ genes in laryngeal squamous cell carcinoma. Pathol Res Pract 201: 557-563, 2005.

19. Takemaru K, Yamaguchi S, Lee YS, Zhang Y, Carthew RW and Moon RT: Chibby, a nuclear $\beta$-catenin-associated antagonist of the Wnt/Wingless pathway. Nature 422: 905-909, 2003.

20. Takemaru K, Fischer V and Li FQ: Fine-tuning of nuclear $\beta$-catenin by Chibby and 14-3-3. Cell Cycle 8: 210-213, 2009.

21. Li FQ, Mofunanya A, Harris K and Takemaru K: Chibby cooperates with 14-3-3 to regulate $\beta$-catenin subcellular distribution and signaling activity. J Cell Biol 181: 1141-1154, 2008.

22. Greaves S: Small changes in Wnt signalling. Nat Cell Biol 5: 387 , 2003.

23. Karakoula K, Suarez-Merino B, Ward S, et al: Real-time quantitative PCR analysis of pediatric ependymomas identifies novel candidate genes including $T P R$ at $1 \mathrm{q} 25$ and $C H I B B Y$ at 22q12-q13. Genes Chromosomes Cancer 47: 1005-1022, 2008.

24. Schuierer MM, Graf E, Takemaru K, Dietmaier W and Bosserhoff AK: Reduced expression of $\beta$-catenin inhibitor Chibby in colon carcinoma cell lines. World J Gastroenterol 12 . 1529-1535, 2006.

25. Kafri T, van Praag H, Ouyang L, Gage FH and Verma IM: A packaging cell line for lentivirus vectors. J Virol 73: 576-584, 1999.

26. Lowry OH, Rosebrough NJ, Farr AL and Randall RJ: Protein measurement with the Folin phenol reagent. J Biol Chem 193 265-275, 1951

27. Pinto D and Clevers H: Wnt control of stem cells and differentiation in the intestinal epithelium. Exp Cell Res 306: 357-363, 2005.

28. Li FQ, Mofunanya A, Fischer V, Hall J and Takemaru K: Nuclear-cytoplasmic shuttling of Chibby controls $\beta$-catenin signaling. Mol Biol Cell 21: 311-322, 2010.
29. Jonas JC, Laybutt R, Steil GM, Trivedi N, Weir GC and Henquin JC: Potential role of the early response gene c-myc in beta-cell adaptation to changes in glucose concentration. Diabetes 50: S137, 2001

30. Fields WR, Desiderio JG, Putnam KP, Bombick DW and Doolittle DJ: Quantification of changes in c-myc mRNA levels in normal human bronchial epithelial (NHBE) and lung adenocarcinoma (A549) cells following chemical treatment. Toxicol Sci 63: 107-114, 2001.

31. Liu T, Peng H, Wu Z and Cui C: Expression and significance of signal transducer and activator of transcription 3 and c-myc in laryngeal squamous cell carcinoma. Lin Chung Er Bi Yan Hou Tou Jing Wai Ke Za Zhi 24: 648-651, 2010 (In Chinese).

32. Krecicki T, Fraczek M, Jelen M, Zatonski T, Szkudlarek T and Dus D: Expression of c-myc oncoprotein in laryngeal squamous cell carcinoma. Acta Otolaryngol 124: 634-637, 2004.

33. Long X, Hu S, Cao P, Liu Z, Zhen H and Cui Y: The expression of oncogene c-myc and its role on human laryngeal cancer. Lin Chung Er Bi Yan Hou Tou Jing Wai Ke Za Zhi 23: 1127-1129, 2009 (In Chinese).

34. Fernando R, Foster JS, Bible A, et al: Breast cancer cell proliferation is inhibited by BAD: regulation of cyclin D1. J Biol Chem 282: 28864-28873, 2007.

35. Fu ZJ, Ma ZY, Wang QR, et al: Overexpression of CyclinD1 and underexpression of p16 correlate with lymph node metastases in laryngeal squamous cell carcinoma in Chinese patients. Clin Exp Metastasis 25: 887-892, 2008.

36. Papadimitrakopoulou V, Izzo JG, Liu DD, et al: Cyclin D1 and cancer development in laryngeal premalignancy patients. Cancer Prev Res (Phila) 2: 14-21, 2009. 